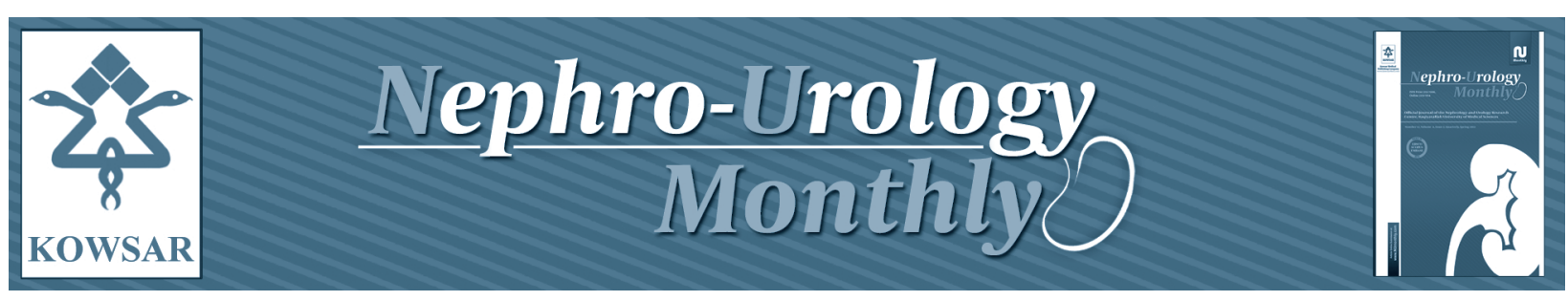

\title{
Transvesical Enucleation of Multiple Leiomyoma of Bladder and Urethra
}

\author{
Alireza Ghadian $^{1^{*}}$, Seyyed Yousef Hoseini ${ }^{2}$ \\ ${ }^{1}$ Nephrology and Urology Research Center, Baqiyatallah University of Medical Sciences, Tehran, IR Iran \\ ${ }^{2}$ Department of Urology, Shahid Modarress Hospital, Shahid Beheshti University of Medical Sciences, Tehran, IR Iran \\ * Corresponding author: Alireza Ghadian, Nephrology and Urology Research Center, Baqiyatallah University of Medical Sciences, Tehran, IR Iran. Tel.: +98- \\ 2181262073, Fax: +98-2181262073, E-mail: p_ghadian@yahoo.com
}

\begin{abstract}
A B S T R A C T
Although bladder leiomyoma is rare, this is the most frequent nonepithelial benign tumor of the bladder. Symptoms and treatment depend on location and size of the lesion as well. The optional treatment is a total enucleation or partial cystectomy, although in biopsy proved cases watchful waiting is an option, surgery should be considered as the tumor grows or symptoms are observed. The etiology of bladder leiomyoma is unknown. Uterine leiomyoma is known to be estrogen responsive. The premenopausal women are prevalent in the fourth decade.
\end{abstract}

Keywords: Leiomyoma; Urinary Bladder; Enucleaion

Copyright ( 2013, Kowsar Corp.; Published by Kowsar Corp.

\section{Introduction}

Although bladder leiomyoma is rare, it is the most frequent nonepithelial benign tumor of the bladder and may arise in any anatomical structure containing smooth muscle (1). Although, most reports about tumors have been found randomly on ultrasonography within the last decade, there has been some exceptional cases of symptomatic leiomyoma reaching dimensions of 3,500 gm (2). Symptoms and treatment depend on location and size of the lesion as well. The optional treatment is a total enucleation or partial cystectomy (3) Growth has been suspected to be influenced by hormones (4).

\section{Case Report}

The patient was a 42 year old woman with partial cystectomy, 15 years ago and myomectomy of uterus, 13 years ago and both pathologic results were leiomyoma. She said that her sister has undergone total abdominal hysterectomy and bilateral salpingoopherectomy due to large myoma of the uterus.

This patient reffered to us with hypovolemic shock (Hemoglobuline: 4.7) resulting from severe gross hematuria that was cured by blood transfusion ( 4 unit packed cell). Evaluation was as follow:

Urine cytology: negative for malignancy

Article type: Case Report; Received:10 Apr 2012, Revised: 18 Apr 2012, Accepted:30 Apr 2012; DOI: 10.5812/numonthly.5122

-Implication for health policy/practice/research/medical education:

Lieomyoma of bladder is a well known disorder that is managed with partial cystectomy, here we represent a new method for management of this disease.

Please cite this paper as:

Ghadian A , Hoseini SY. Giant Ureteral Transvesical Enucleation of Multiple Leiomyoma of Bladder and Urethra. Nephro-Urol Mon.2013;5(1): 709-711. DOI: 10.5812/numonthly.5122

Copyright @ 2013, Kowsar Corp.; Published by Kowsar Corp.

This is an Open Access article distributed under the terms of the Creative Commons Attribution License (http://creativecommons.org/licenses/by/3.0), which permits unrestricted use, distribution, and reproduction in any medium, provided the original work is properly cited. 
IVU: normal kidneys with large mass in the base of bladder ( Figure 1)

Transvaginal ultrasonography: myoma of the uterus

CT scan: multiple solid masses between bladder, uterus and vagina ( Figure 2 )

Cystoscopy: large tumor in right hemitrigone and bladder neck with intact bladder mucosa and varicose vessels in the bladder neck and base of the bladder

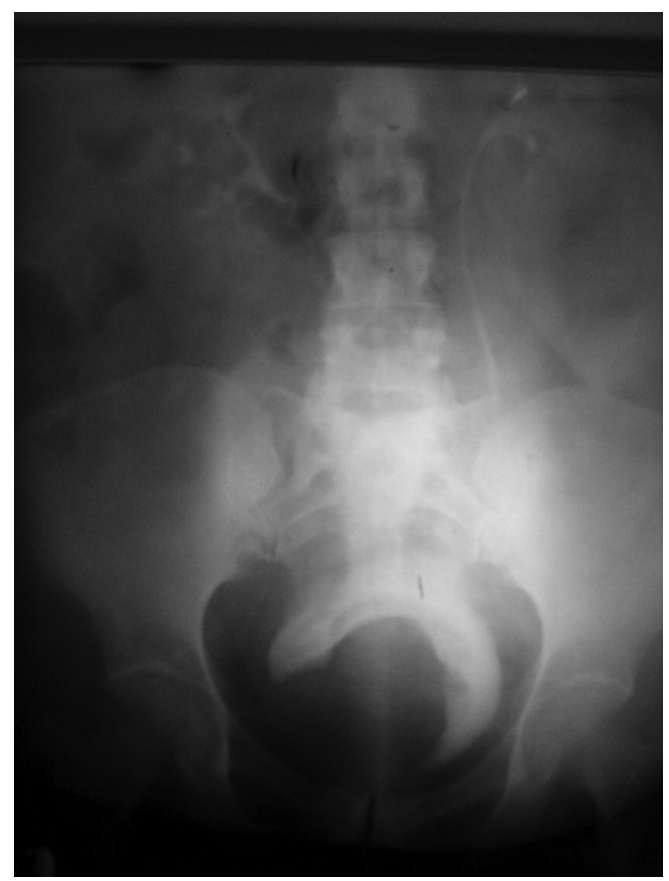

Figure 1. IVU Shows Normal Kidneys With Large Mass in the Base of Bladder

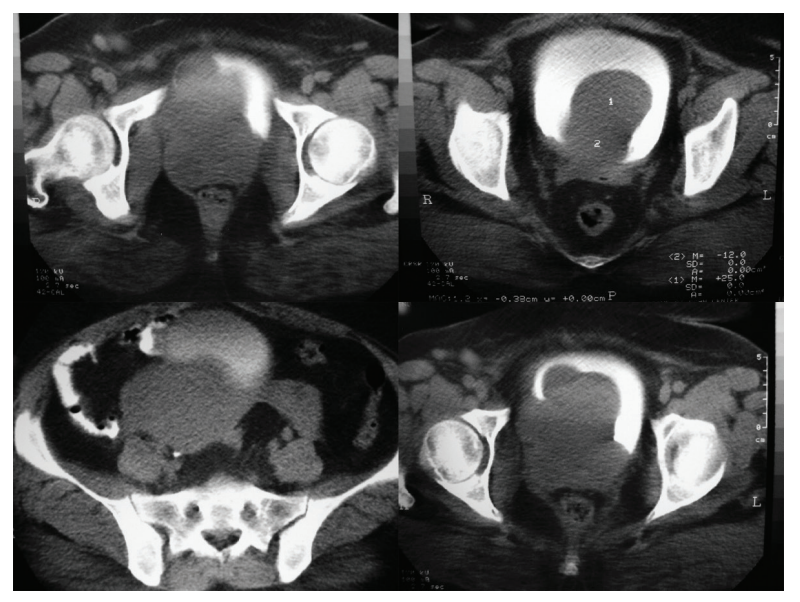

Figure 2. CT Scan Shows Multiple Solid Masses Between Bladder, Uterus and Vagina

By means of laparotomy and multiple encapsulated masses within bladder, urethra, uterus and vagina were diagnosed and gynecologists performed hysterectomy and enucleation of vaginal leiomyoma and then we performed, transvesically, enucleation of bladder and urethral masses. Seven tumors were in bladder and urethra that have $170 \mathrm{gr}$ weight. The pathologic report was leiomyoma.

\section{Discussion}

The etiology of bladder leiomyoma is unknown. Uterine leiomyoma is known to be estrogen responsive, in which the pathological findings are similar to those in bladder leiomyoma (5).

Genitourinary leiomyoma's may occur in the bladder, kidney, epididymis, penis, prostate, scrotum, seminal vesicles and spermatic cord (4). The premenopausal women are prevalent in the fourth decade (6).

According to the literature, immediate surgery is the optional treatment in patients with leiomyoma. In biopsy proved cases watchful waiting is an option but surgery should be considered as the tumor grows or symptoms are observed $(2,3)$. Although surgical excision should be curative, the use of GnRH may be another choice for the treatment of bladder leiomyoma as the same in the uterine leiomyoma (5). This therapy will be especially useful for women who still have ovarian function and have undergone myomectomy but wish to prevent recurrence or the development of an additional leiomyoma $(7,8)$.

\section{Conclusion}

Hematuria is an uncommon symptom of bladder leiomyoma, and in this case, compression of pelvic veins with large tumors and impairment of sub mucosal bladder vessel drainage, results in active hemorrhage of these vessels and severe gross hematuria that leads to hypovulemic shock.

To avoid injury of bladder nerves and external sphincter, transvesical enucleation of these tumors are suggeted. In this case,although huge tumors were placed in the trigone, bladder neck and posterior surface of urethra, the patient was ,contented after transvesical enucleation of tumors. Therfore, we recommend to perform transvesical enucleation of tumors in these sites and avoid from retrovesical and bladder neck dissection.

\section{Acknowledgements}

None declared.

\section{Authors' Contribution}

None declared.

\section{Financial Disclosure}

None declared. 


\section{Funding/Support}

None declared.

\section{References}

1. Cornella JL, Larson TR, Lee RA, Magrina JF, Kammerer-Doak D. Leiomyoma of the female urethra and bladder: report of twentythree patients and review of the literature. Am J Obstet Gynecol. 1997; 176(6):1278-85.

2. Broessner C, Klingler CH, Bayer G, Pycha A, Kuber W. A 3,500gram leiomyoma of the bladder: case report on a 3-year followup after surgical enucleation. Urol Int. 1998;61(3):175-7.

3. Naganuma T, Yasumoto R, Kawano M, Yamakoshi Y, Masuda C, Kyo M, et al. [Leiomyoma of the bladder: report of two cases]. Hinyokika Kiyo. 1998;44(11):833-7.
4. Alvarado-Cabrero I, Candanedo-Gonzalez F, Sosa-Romero A. Leiomyoma of the urethra in a Mexican woman: a rare neoplasm associated with the expression of estrogen receptors by immunohistochemistry. Arch Med Res. 2001;32(1):88-90.

5. Haney AF. Clinical decision making regarding leiomyomata: what we need in the next millenium. Environ Health Perspect. 2000;108(Suppl 5):835-9.

6. Joshi HB, Beck RO. Leiomyoma of the female urethra with upper tract dilation and treatment with transurethral resection: a case report and literature review. Tech Urol. 2000;6(3):223-5.

7. Furuhashi M, Suganuma N. Recurrent bladder leiomyoma with ovarian steroid hormone receptors. J Urol. 2002;167(3):1399-400.

8. SajjadNazir S, Maqbool A, Khan M. Leiomyoma of the Urinary Bladder-A Case Report and Brief Review of Literature. Nephro-Urol Mon. 2009;1(1):72-4. 